\title{
Effects of Perspective on Consumers' Judgment of Marketplace Transgression: An Abstract
}

\author{
Ruby Q. Saine and Sajeev Varki
}

\begin{abstract}
Consumer transgression is an emerging field of study within service marketing (Fullerton and Punj 2004; Harris and Reynolds 2004; Jones et al. 2011; Lovelock 1994; Tonglet 2002). Some of the topics that service scholars have examined include contagious effects of consumer transgressions in access-based services such as car sharing (Schaefers et al. forthcoming), territorial behaviors (Griffiths and Gilly 2012), customer rage (Surachartkumtonkun et al. 2014), spectator rage (Grove et al. 2013), employees dealing with dysfunctional customer behavior (Gong et al. 2014; Harris and Reynolds 2003), snubs and betrayals in relationship transgression (Jones et al. 2011), theft (Cox et al. 1993; Tonglet 2002), and consumer retaliation as a response to dissatisfaction (Huefner and Hunt 2000). However, there is scarce research on how consumers view their own misbehavior and how managers could influence consumers' own view of their misbehavior. In addition, whereas past service literature focuses on identifying the antecedents, consequences, and typologies of consumer transgressions in specific service sectors (Harris and Daunt 2011), studies investigating the cognitive processes underlying customer transgressions remain lacking (Fisk et al. 2010; Schaefers et al. forthcoming). This study fills these gaps in the service literature.

We seek to extend this literature and propose that consumers will make more stringent self-judgment if they adopt a third-person perspective when imagining a service scenario. Across a series of studies, we find evidence that relative to the first-person perspective, the third-person perspective motivates moral stringency by increasing principle-based reasoning or deontological reasoning and judgments of immorality. Our findings can be used in advertising and design of service layout to lower incidents of customer misbehaviors.
\end{abstract}

References available upon request.

\author{
R.Q. Saine $(\bowtie) \bullet$ S. Varki \\ University of South Florida, Tampa, FL, USA \\ e-mail: qin@usf.edu; svarki@usf.edu
}

